\title{
Ecosystem-Based Fisheries Management Approach: Before After Control Impact Design in Managing Mangroves Ecosystem
}

\author{
Mohd Fadzil Shuhaimi bin Ramli \\ Faculty of Science and Biotechnology, University of Selangor, Bestari Jaya, Selangor, MALAYSIA.
}

\begin{abstract}
Ecosystem-based approach in fisheries management is still a new concept in fisheries management in Malaysia. This is in contrast to 'traditional' approach adopted by Department of Fisheries (DOF) mainly to suppress fishing effort through the enforcement of the Fisheries Act 1985. It was later admitted that the approach had failed to meet its objective. This paper describes the implementation of ecosystem approach in managing the mangroves ecosystem using the Before After Control Impact (BACI) design to detect the cause of perturbation as a result of management decision. If the cause of the perturbation is confirmed, and it is caused by the management decision, then the decision is to be reconsidered. The pilot project proposed is to assess the suitability, preparedness and the acceptance of the eco-approach by society and the authority. In managing mangroves ecosystem, both society and the authority sit together in a committee to formulate a management plan that in general oversees the wellbeing of the mangroves benefiters using scientific data and knowledge.
\end{abstract}

Keywords: BACI, mangroves ecosystem, ecosystem-based

\section{Introduction}

In Malaysia, the fisheries management approach as practiced by the Department of Fisheries (DOF) revolves around the endeavour of suppressing fishing effort. The aim was initially to stabilize the fishing effort or if possible to reduce it. Since 1981, the promulgated New Licensing Policy [1] vigorously implemented the 'no-more issuance of new licenses' policy firstly by turning-down new application for the licenses nationwide. Secondly, a careful and schematic plan was drawn to suppress the advancement of fishing effort with respect to vessels capacity and engine power, zoning of fishing areas and controlling of the number of fishermen by registration exercise. Lately, it was found that the implementation of the policy failed to produce expected result as according to fisheries researchers, the fisheries resources have never been better since the beginning [2]. Moreover, fishing effort which was supposed to decline or plateau long time ago continues to show fluctuation, an evidence of failure of implementation of the policy [3]. Thus, exit-plan is introduced and implemented to reduce the number of vessels by buying them from the owners and turning the vessels into the artificial reef. We have yet to see if this brilliance scheme ever to produce redeemable result.

It is hard to categorize the fisheries management as presently practiced since the emergence of the Fisheries Act 1985 about 27 years ago as scientifically-based or societal-based or a mixture of both. Sometime we are at the stage of uncertainties for are we pursuing the adaptive management approach or the precautionary approach [4] or the mixture of both. Then, there is an immense problem of a gap between scientists and fisheries managers with regard to the limit of the fishing effort. Scientists based their proposal on scientific findings whereas managers have to deal with social-economic, political and pressure from the public. Thus the gap would never been made closer sometime even creating impasse between the two groups. Perhaps, eco-system based approach may provide an answer for fisheries management that truly encompasses the whole bundle of approaches.

The objective of this paper is firstly to introduce alternative approach in fisheries management touching on the concept of ecosystem-based approach on a unit of ecosystem, that is, the mangroves ecosystem. Secondly, the objective is to describe Before After Control Impact (BACI) design that detect the cause of the perturbation in assisting decision making.

\section{Ecosystem-based approach}

Ecosystem-based approach though was first coined in the early 80's and formally accepted at the Earth Summit in Rio in 1992 [5], the phrase was for the first time heard by most fisheries officers at the Annual Senior Fisheries Officers Conference held in , Kota Bharu, Kelantan on the $8-11$ June, 2009. Someone at the conference brought up the issue of the management approach as something that is gaining popularity among the developed nations. Moreover, he envisioned that the new approach is going to be obligatory in light of recent trend of serious concern on the environmental exploitation. The chair of the conference, the Director General of 
Fisheries, Dato' Junaidi bin Che Ayub, then requested the delegates to seriously consider this new approach to the fisheries management.

Eco-system based approach or in short, eco-approach can be regarded as new and scientifically-based approach in contrast to the 'traditional' fisheries management ${ }^{1}$. It is geographically specified, adaptive, takes account of ecosystem knowledge and uncertainties, considers multiple external influences, and strives to balance diverse societal objectives [6]. In fisheries context as put by Food and Agricultural Organization (FAO), suffice to say that the management approach is to ensure the ecosystem continues to produce food indefinitely and made sustainable for the benefit of mankind as well as ecosystem wellbeing [7]. The eco-approach is how decisions made by managers do not adversely affect the ecosystem function and productivity [8].

There is the question of what exactly the eco-approach is and how it is going to be implemented. We know there is a binding connection between ecosystem and fisheries management at large but what is the management frame-work like. In this respect, scientists and managers must work hand-in-hand with the common objective of protecting the ecosystem. For instance, if trawlers do proven scientifically to disturb fish breeding grounds of the particular area, then the probable action is to either stop trawling altogether or reduce their number or introduce seasonal fishing. This is the scenario of eco-approach and a straight forward one.

Let examine another area of eco-approach, i.e., the management of mangroves ecosystem in relation to fisheries management. This is the suggestion on how the eco-approach is to be implemented and by no mean exhaustive.

\section{Management of mangroves ecosystem}

The fundamental in this approach is not to manage or manipulate the ecosystem processes but rather to prevent our action from deteriorating or destroying it. So we must begin firstly by establishing the baseline data and periodically collecting them to establish a time series data. The objective is to detect deterioration of the ecosystem as a result of the decision made so that we very well know when to stop. Better understanding of how the implementation of eco- approach is represented here; a unit eco-system, i.e., the mangroves are chosen because it is a perfect representation of an ecosystem which is defined as a geographically specified system of organisms (including humans), the environment, and the processes that control its dynamics [6]. Let us first describe the ecosystem, it relationship with fish abundance and later on how we achieve to protect, monitor and sustain the ecosystem in scientific manner. A common sense will tell us that mangroves protection is not entirely rests on how well the plan is but how the integration effort among relevant agencies connected with the responsibility to protect the environment. Fig. 1 summarizes the processes of the eco-approach, beginning with the management decision on establishing policy, methodology and direction. It will end with the management decision whether it is necessary to alter the previous decision made.

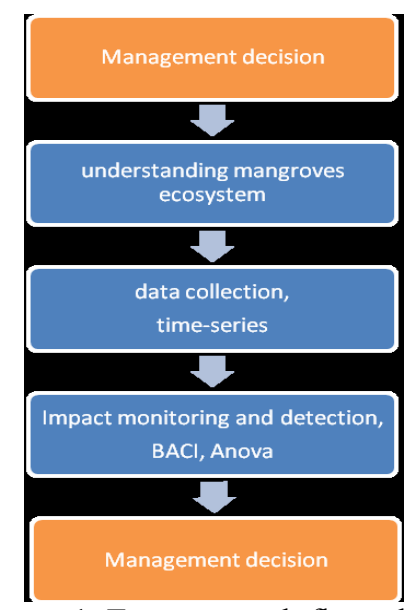

Figure 1: Eco-approach flow-chart

\subsection{Mangroves ecosystem}

Mangroves and fish abundance are closely interrelated. Reference [9] estimated that the $20 \%$ loss of mangroves could cause about 70,000 tones of prawns loss valued at RM 300 million. However, fish abundances are not only affected by the deterioration of mangroves, they are very much influenced by the environmental changes as well particularly that are caused by pollution and other impacts originated from human activities.

${ }^{1}$ The current fisheries management approach as practiced by DOF is considered 'traditional'. 
Dead leaves of the mangroves fall onto the sea then undergoing the decaying processes. As the bodies of organisms decay they become dispersed into fragments and dissolving materials, collectively called organic detritus [10]. Dissolved organic matter (DOM) and particulate organic matter are two forms of detritus. These mangrove detritus are then consumed by herbivores and omnivores, beginning with very small sized invertebrates and ending with such species as worms, mollusks, prawns and crabs, which in turn are preyed upon by lower carnivores. The food chain ends with higher carnivores such as large fish, birds of prey, wild cats or man himself [11].

\subsection{Detecting impacts}

Clearly, mangroves play an important role in ensuring continuous food supply to the fishes and due to its fragile nature, it is easily disturbed and to the extent of being destroyed. Thus managers need to establish a system whereby they could detect such harassment to the ecosystem and finding remedy to correct the damage. The task is to investigate whether the 'management decisions' had produced such impacts but the method used is indirect where the stressors or impacts are typically unknown and the analysis is used to produce the stress gradients from data on abundance [12]. If there is a difference in abundances between the impacted and the control populations, before and after the decisions made, then it can be deduced that the difference is in fact caused by the 'decisions' themselves.

For example, if we decide to give away mangroves for aquaculture, then the probable impact will be declining in fish landings but it could also caused by other factors such as pollution, or overfishing. To really detect the cause of the decline, the BACI was introduced as in [13] where according to him, the simplest approach of detecting impact is to observe, say, abundance change Before the introduction of the disturbance and then to compare it with the abundance After at the impact site and it involves the collection of data prior to the activity and compares it with data after the activity. In [13] optimal impact study design, he suggested a design with at least one time of sampling before and at least one after the impact begins, at least two locations differing in degree of impact, and measurements on an environmental as well as a biological variable set in association with each other. A significant change of the abundance can then be attributed to the present of the disturbance, but as in [14], any differences from Before to After the potential disturbance may occur between the two times of sampling, but may not be related to (caused by) the human activity. This design was later extended as in [15] who argued that the assessment problem can indeed be solved by taking replicates over time and only by sampling at many different times, both Before and After start-up, the variability due to all sources, both sampling error and random population fluctuations can be estimated. The design requires collecting samples simultaneously at both the Impact site and a nearby "control" site several times before and after impact and thus the word "paired" emerged for sampling at both sites to be to at the same time. Hence, BACIP is an acronym used for the paired design to differentiate it from the unpaired design. Since the state of the system in the absence of the effect cannot be observed after the disturbance, there is need to estimate statistically with the observed (perturbed) condition [16]. The BACIP design accomplishes this by collecting samples at both the Impact site and a nearby "Control" site where they are sampled simultaneously thus pairing them together. The samples are collected at interval of times (time series) for a periods of before and after the disturbance and the time series data serve as replicates of the assessment design.

Further extension of the Before-After impact design also known as "Beyond BACl" design was proposed as in [17], who argued that any location-specific temporal difference that occurs between the two locations will be interpreted as an impact even if it has nothing to do with the human disturbance and thus suggested the use of multiple control sites. The set of locations chosen to serve as Controls must simply represent the range of the habitats of the one that might be disturbed (the Impact location) [18]. "Beyond BACI" design is therefore a series of random sampling in time and space in the impacted zone and in two or more controls which would be confronted through a asymmetric analysis of variance (ANOVA) [19].

\subsection{Managing mangroves}

Mangroves protection does not come under the jurisdiction of the Fisheries act 1985. It means, DOF is not the authority that oversees the wellbeing of the mangroves. Consequently, DOF must seek the assistance of other agencies that directly involve with the protection of the mangroves particularly the Department of Forestry. Since polluting is an offence in almost anywhere in the country thus the role of the Department of Environment is crucial in the mangroves management. Clearly now that mangroves are to be collectively managed by more than one agency and the best method is to form a working committee that is given the necessary authority to implement the protection and conservation plan of the mangroves. Apart from the agencies mentioned earlier, other agencies may somehow or rather have role to play such as the District Office, Department of Irrigation and Drainage, Local Authority and Marine Police. To allow the involvement of local inhabitants through the concept of community-based management, their representatives from the Fisheries Association, village headman and other fisheries related bodies are invited to be members of the committee. 


\subsection{Pilot project}

The purpose of having a pilot project is to assess the suitability, preparedness and the acceptance of the eco-approach by society and the authority .The initial step is to prepare an Ecosystem-based Fisheries Management Plan (the Plan). The scope of the Plan may not be national and it is suggested to be localized covering areas given high priority in resource and ecosystem protection, and significant in socio-economic values.

It is expected that fisheries managers of DOF having little or zero knowledge of the fundamentals of the eco- approach. Therefore a workshop is to be held with the objectives of providing information, knowledge and guideline of the eco-approach. Several speakers from local universities and abroad will be invited to give talk on several related topics and to conduct the workshop. Exchange of data, experiences and cooperation among agencies is expected. The participants of the workshop will also include several officers/managers of other government agencies and Nongovernmental Organizations (NGO's). The workshop will emphasize towards construction of the contents of the Plan.

Following the workshop, a working committee is selected with its main objective is to produce the Plan. Several members of the working committee will also pay a visit to National Oceanic and Atmospheric Administration (NOAA) Fisheries in USA to gain more knowledge on the implementation of the approach. The 'Strategic Guidance for Implementing an Ecosystem-based Approach to Fisheries Management' prepared by the Ecosystem Approach task Force for the Marine Fisheries Advisory Committee (MAFAC) as in [20] will serve as the reference. The task of MAFAC is to advise NOAA Fisheries on the implementation of the approach.

\section{Conclusion}

Eco-approach, among other things, will end the myth that fish depletion is caused solely by trawlers encroachment. With proper and consistent monitoring of habitats changes, food-web studies and environmental degradation, we will know the real culprit behind the perturbed fish resources. Hence, in-depth scientific knowledge on the ecosystem itself is paramount in eco-approach. Decision makers, on the other hand, must place scientific basis at the top of the list.

To summarize, the implementation of eco-approach should be collectively managed by a committee comprises of various agencies and local society which its primary task is to formulate a management plan. In this example, since there is evidence of strong relationship between mangroves and fish abundance, there is a dire need to protect the former from being degraded. The method known as BACI is introduced as a tool to detect changes of mangroves degradation as well as fish abundance. The committee must emphasize on data collection so that the before data can be compared to after data and analyzed statistically to decide if the decision made by fisheries managers is detrimental to fish abundance.

\section{Acknowledgment}

The author wishes to thank the University of Selangor in general and the Dean of Faculty of Science and Biotechnology in particular for encouragement and assistance given during the preparation of this paper.

\section{REFERENCES}

[1] C. P. Ean (1987) The small purse seine fishery of Kampong Gajah, Penang and Tanjung Piandang, Perak, Fisheries Bulletin no.48, Dept. of Fisheries, Malaysia.

[2] MFRDM (2000) Fisheries resource survey in the exclusive economic zone (EEZ) of Malaysia 1997-1999 (ISBN 983-9819-18-6). Kuala Lumpur; Marine Resource Development and Management, Department of Fisheries, Ministry of Agriculture Malaysia.

[3] Fisheries Annual Statistics 1990 -2007

[4] http://www.jncc.gov.uk/page-1576 dated 27 August 2009

[5] United Nations (1992). Convention on Biological Diversity. UN, New York. 31pp.

[6] ecosystembasedmanagement.com dated 26 August 2009

[7] www.jncc.gov.uk/page-1576 dated 27 August 2009

[8] http://jncc.defra.gov.uk/page-2518-theme=textonly dated 19 Oct 2012

[9] MOSTE (2000). Malaysia 'Initial National Communication' submitted to the United Nations Framework Convention on Climate Change. Ministry of Science, Technology \& Environment, Malaysia. July 2000

[10] Odum, Eugene P.( 1993 ) Ecology and Our Endangered Life-Support Systems. (Sinauer Associates, Inc. Publishers, Sunderland, Massachusetts pp. 47)

[11] FAO (1994) Mangrove Forest Management Guidelines. FAO Forestry Paper No.117.Rome.Smith, Eric P. (2002). Ecological statistics. In El-Shaarawi, Abdel H. and Piegorsch, Walter W.(eds. ), Encyclopedia of environmetrics (Volume 2, pp. 589-602). Chichester: John Wiley \& Sons Ltd.

[12] Smith, Eric P. (2002). Ecological statistics. In El-Shaarawi, Abdel H. and Piegorsch, Walter W.(eds. ), Encyclopedia of environmetrics (Volume 2, pp. 589-602). Chichester: John Wiley\& Sons Ltd.

[13] Green, R.H. (1979). Sampling design statistical methods for environmental biologist. (Chichester:Wiley)

[14] Hurlbert, S. H. (1984) Pseudoreplication and the design of ecological field experiments, Ecological Monographs, 54 (2): $187-211$.

[15] Strewart-Oaten, A., Murdoch, W. R. and Parker, K. R. (1986) Environmental impact assessment "pseudoreplication" in time?, Ecology, 67:929-940.

[16] Stewart-Oaten, A., Bence, J. R. and Osenberg, C. W. (1992) Assessing effects of unreplicated perturbations: No simple solution, Ecology, 73:1396-1404. 
[17] Underwood, A.J. (1992) Beyond BACI: The detection of environment impacts on populations in the real, but variable, world, $J$. Experimental Marine Biology and Ecology, 161: 145-178.

[18] Underwood, A. J. (1994) On beyond BACI: sampling designs that might reliably detect environmental disturbances, Ecological Applications, 4:3-15

[19] Santos, Tiago, Cunha, Isabel and Weber, Mike (2002). A "beyond BACI" study of Agunsa's breakwater in North Portugal. Littoral 2002, The Changing Coast. EUROCOAST/EUCC, Porto-Portugal, ed. EUROCOAST- Portugal, ISBN 972-8558-09-0.

[20] Busch, W.-D.N., B.L. Brown, and G.F. Mayer (Eds). 2003. Strategic Guidance for Implementing an Ecosystem-based Approach to Fisheries Management. United States Department of Commerce, National Oceanic and Atmospheric Administration, NMFS, Silver Spring, MD 62p. 